\title{
Buried Rubber Band: A Cause of Persistent Penile Discharge, Recurrent Urinary Tract Infections, and Development of Urethrocutaneous Fistula
}

\author{
Amer Karim* \\ Senior House Surgeon, Institute of Urology, London \\ E-mail: amerkarim@e320.freeserve.co.uk
}

Received May 2, 2004; Accepted August 3, 2004; Published August 13, 2004

KEYWORDS: urethral discharge, penile incarceration, fistula, urinary tract infection

DOMAINS: urology

\section{CASE REPORT}

An 88-year-old man with no previous urological history was referred with profuse offensive urethral discharge. He gave a 2-year history of recurrent urinary tract infections and increasing difficulty and pain retracting his foreskin.

On examination, he was noted to have a very tight, erythematous painful foreskin. Urinalysis was normal and previous penile swabs and urine cultures had grown no organisms. He was resultantly counseled and listed for a routine circumcision.

At operation, the foreskin was retracted and during the dissection process, a tight rubber band (Fig. 1) was discovered buried within the mucosa (Fig. 2), under newly epithelialized skin. It was found to completely encircle the glans penis, creating a band of infected ulcerated tissue that had resulted in the formation of a small urethrocutaneous fistula. The elastic band was cut and removed and the defect was closed with absorbable sutures.

Following the operation, the patient denied any history of erectile dysfunction and did not recall ever placing the rubber band around his penis. He went on to make a full recovery and was subsequently discharged.

\section{COMMENTS}

Penile incarceration should be considered a surgical emergency, as early decompression is associated with fewer complications secondary to penile devascularization, urinary retention, and urethral damage[1]. Solid rings are most commonly implicated, but hidden foreign bodies are also a rare cause of strangulation and urethrocutaneous fistula. 


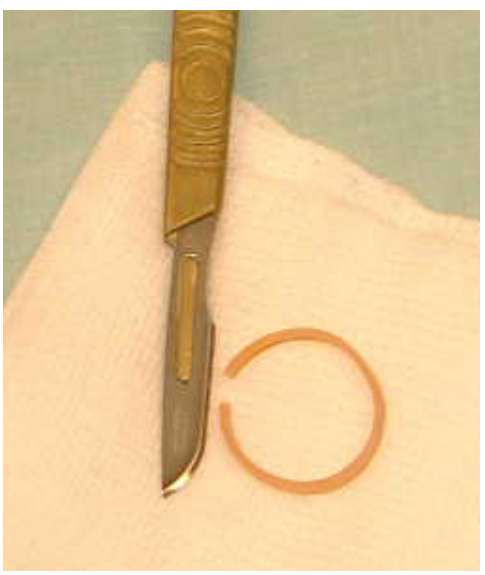

FIGURE 1

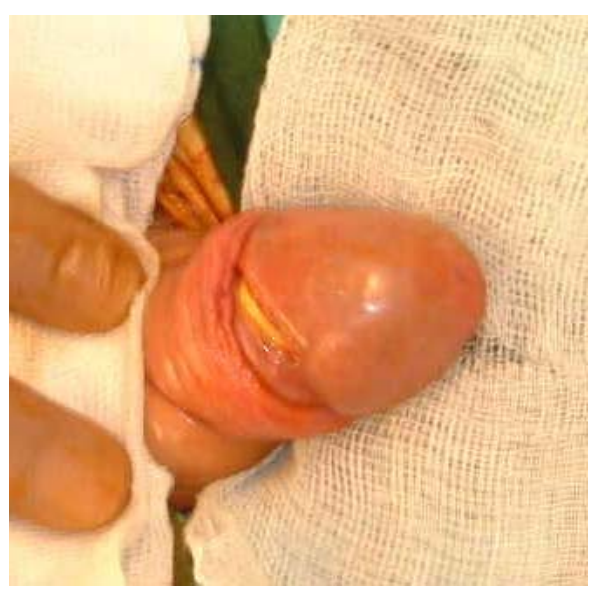

FIGURE 2

\section{REFERENCE}

1. Du, J.N. (1984) Foreign-body implants in the foreskin. Can. Med. Assoc. J. 130(7), 845-846.

This article should be referenced as follows:

Karim, A. (2004) Buried rubber band: a cause of persistent penile discharge, recurrent urinary tract infections, and development of urethrocutaneous fistula. TheScientificWorldJOURNAL 4, 655-656.

\section{Handling Editor:}

Anthony Atala, Principal Editor for Urology — a domain of TheScientificWorldJOURNAL. 


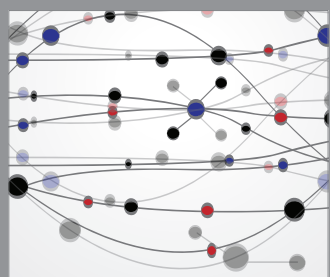

The Scientific World Journal
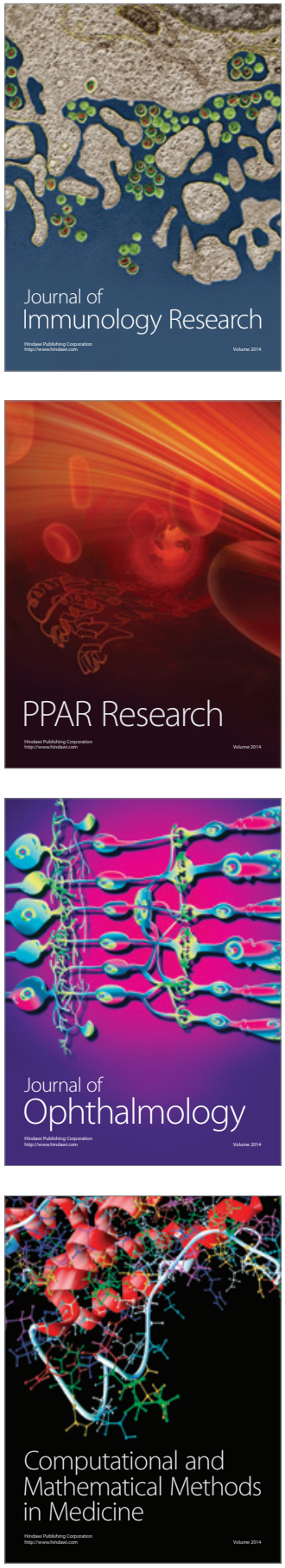

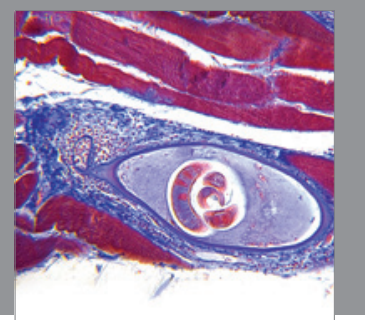

Gastroenterology

Research and Practice
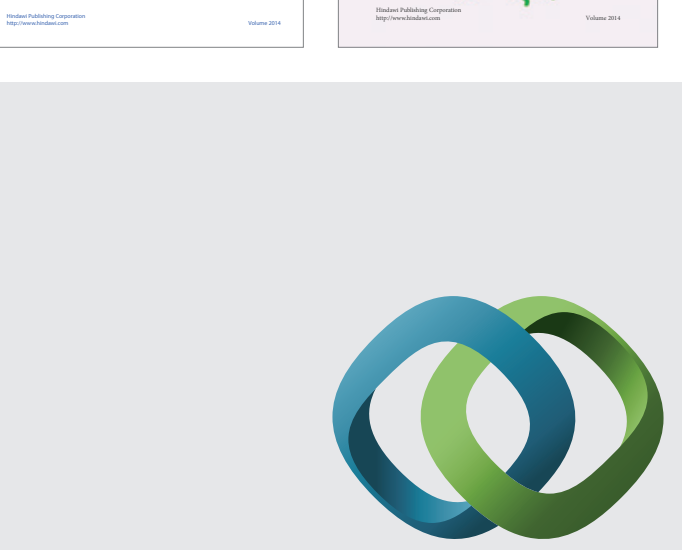

\section{Hindawi}

Submit your manuscripts at

http://www.hindawi.com
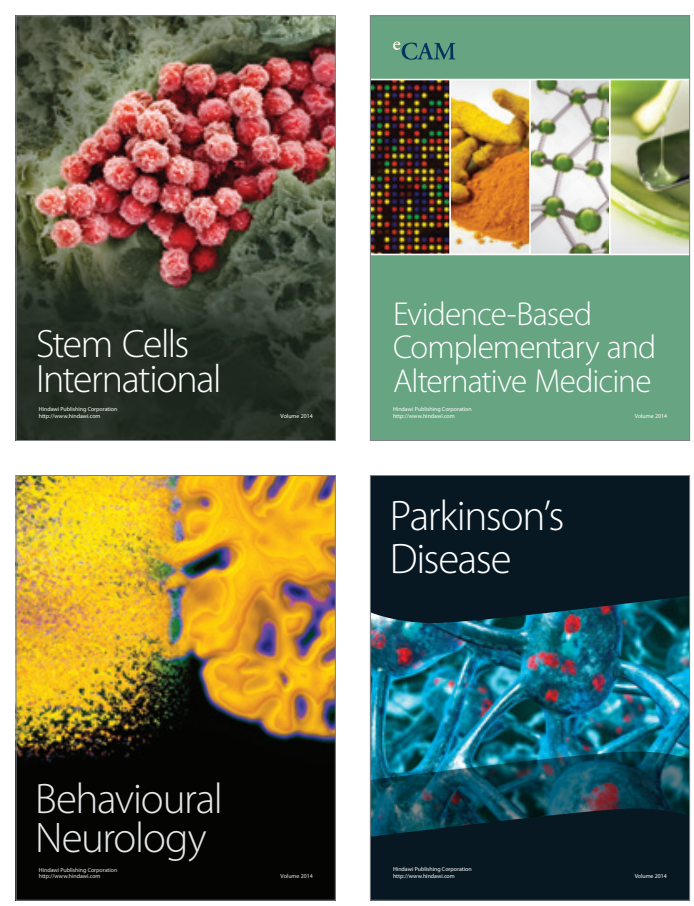

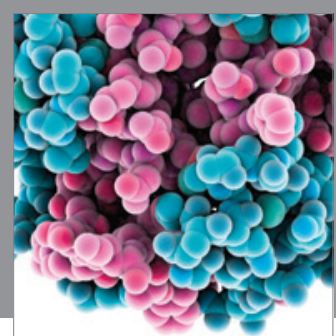

Journal of
Diabetes Research

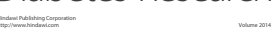

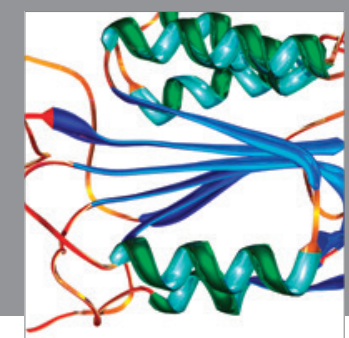

Disease Markers
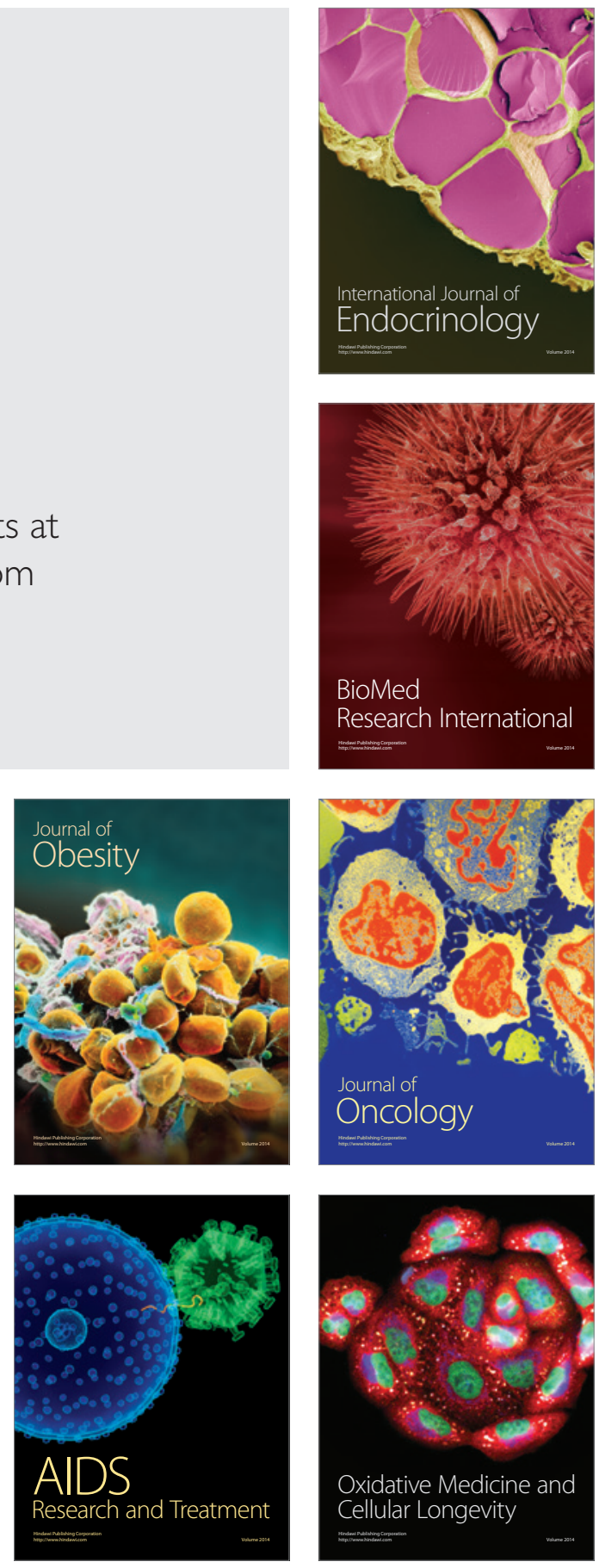